\title{
Foreign Exchange Risk and Profit Improvement in the Comprehensive Profit Opportunity and Lost Opportunity Control Model
}

\author{
Akira Nishimura $^{1}$ \\ ${ }^{1}$ Faculty of International Business Management, Beppu University, Japan \\ Correspondence: Akira Nishimura, Faculty of International Business Management, Beppu University, Japan. \\ E-mail: ZTD03361@nifty.com
}

Received: January 20, 2016

Accepted: February 4, 2016

Online Published: March 15, 2016

doi:10.5539/ijbm.v11n4p1

URL: http://dx.doi.org/10.5539/ijbm.v11n4p1

\begin{abstract}
The aim of this paper is to examine the influence of foreign exchange risks on manufacturing activities (monozukuri in Japanese) and the function of derivatives as a countermeasure against such risk from the viewpoint of management accounting. From this perspective, we examine the Comprehensive Profit Opportunity and Lost Opportunity Control (COLC) model, discussed previously in this journal, and further its practical development and application. To this end, this paper first clarifies the actual situations of major Japanese manufacturing companies in terms of foreign exchange fluctuation earnings and derivative instruments (including hedge accounting). Then, after investigation of the prior research on the interrelation between risk management and management accounting, we theoretically analyze the relations between risks, derivatives, and hedge accounting from the synthetic viewpoint of profit opportunity, risk, and opportunity cost. As a result, this analysis can play an important role in outlining the landscape in which business strategy and enterprise risk management align, both proactively and reflectively, with contemporary management accounting.
\end{abstract}

Keywords: derivatives, foreign exchange risk, hedge accounting, lost opportunity, internalized improvement, profit opportunity

\section{Introduction}

The function and content of management accounting has been changing since the global financial crisis of 2008 . For example, in Japan, cost design (also known as target costing in English) has contributed to innovation in manufacturing activities (monozukuri) and improvement in business results through organically integrating low cost with high quality since the 1960s. In recent years, this tool is now taking a new form that is more suitable for coping with financial risks and can adapt to changes in the business environment (Nishimura, 2014; Tanaka, 2015). Manufacturing enterprises that adopt cost design now face a critical problem: how to protect their manufacturing activities from financial risks, primarily market risks such as foreign exchange risk, interest rate risk, and commodity price risk. At present, management accounting cannot exist independently of risk management, derivatives strategy, and hedge accounting, as these must be disclosed and known. Management accounting, beyond its original functions of efficiency and effectiveness, should also be a tool for planning for and controlling financial risks that may harm manufacturing activities. The profit opportunities of derivatives can act as a countermeasure to these risks. Before and after the recent global financial crisis, many enterprises had the bitter experience of sacrificing sustainable and long-term manufacturing performance to the speculation of short-term derivatives. In this sense, all manufacturing enterprises are now confronted by a critical problem: how to manage the relations between manufacturing activities and external financial risk (particularly foreign exchange risk) by using effective management and accounting systems. This problem is also related to derivatives strategy and enterprise risk management.

Although management accounting, with the original goal of efficient and effective management, did not include risk as a main subject in the past, management accounting has always been influenced by uncertainty. Enterprises have managed uncertainty in management accounting by means of variance analysis (the recognition of uncontrollable factors) and improved decision-making and performance evaluation methods (relativized planned-value and the acceptance of non-programed activity) since the beginning of the twentieth century. At present, uncertainty is deeply intertwined with financial risk, including foreign exchange risk, which is the primary and inextricable issue on the agenda of contemporary management accounting. In contrast, in the past, 
risk was generally recognized as controllable through traditional planning and control systems (Nishimura, 2011) Management accounting is shifting from the partial modification of decision-making and performance evaluation to the retrospective and perspective systematization and synthetization of decision-making and performance evaluation with enterprise risk management and hedge accounting.

Against this background, manufacturing enterprises should pay greater attention to market risks, and particularly to the risk of foreign exchange volatility, which strongly influences manufacturing activities. This should be done not only to protect their activities from these negative effects, but also to build up a stable manufacturing foundation that overcomes external financial risks by means of profit improvements in terms of revenue, purchasing, and cost improvements. Therefore, those employing management accounting in globally competitive manufacturing enterprises must also recognize the relations between market risks, derivatives as countermeasures against those risks, and manufacturing activities, using this recognition to insert them into a newly transformed planning and control system to improve the use of information, measurement, and communication (Nishimura, 2015a).

In this paper, we aim to clarify the problems and roles of contemporary management accounting in connection with foreign exchange risks, derivatives and profit improvements, and their relations. Therefore, to make clear the actual situation of foreign exchange risks and derivatives, we first analyze the financial statements and data of major listed manufacturing enterprises in Japan. We also examine the prior literature on the general interrelation between risk management and management accounting and, with reference to this issue, introduce the COLC model, which was addressed in the previous issue of this journal (Vol. 10 No. 8: Nishimura, 2015a). Second, on the basis of this COLC model, we examine hedge accounting and foreign exchange risk management from the viewpoint of profit opportunity and lost opportunity, using this to further clarify the more practical and specialized form of the model useful in today's risk environments. Lastly, through this investigation, we elucidate the main purpose and the changing features of contemporary management accounting.

\section{Prior Research and Literature}

\subsection{Literature on the Interrelation between Risk Management and Management Accounting}

Management accounting researchers have not fully elucidated "the general relationship between management accounting and risk management" (Bhimani, 2009, p. 2) and have clarified the relation between management accounting and some specific risks (such as foreign exchange risk) even less. Developing this understanding is important to allow basic recognition of the effects of external risks on manufacturing activities. As Kim and Collier (2013) point out, because of our weak recognition of the operational risks and external risks facing organizations during the global financial crisis, "with a few exceptions, we have relatively little understanding about the (complex) interrelation between risk, risk management, and management accounting and control practices" (p. 84). Few studies have been carried out on this topic, and it is important that, as a first step, we understand the interrelations.

Shank and Miguel (2009) propose that management accounting provides managers with a comprehensive and enterprise-wide information system that can warn of impending disasters. Management accounting makes it possible to prepare broad information, including both financial and non-financial information, on past and future performance. Rasid, Isa, and Ismail (2014) also mention that "besides information that is broad in scope, management accounting information that is timely, integrated and aggregated is essential for risk management" (p. 140). At the same time, as Kim and Collier (2013) point out, management accounting is more strongly inclined to consider risk information than cost.

Woods (2008) contends that strategy is organizationally combined with risk information by integrating four perspectives (financial, customer, internal business process, and learning and growth) in a Balanced Score Card (BSCD) with risk management. Through these factors and on the basis of risk awareness, senior managers can make a strategic decision comprehensively and establish an effective control system over the whole organization, while those at the operational level not only carry out the enterprise strategy and objectives but also control operational risks, maintaining strategic and risk awareness in doing so. Seal (2006), on the basis of institutional theory of agency, notes the routing aspect in management accounting and discusses its important role in restricting senior managers' arbitrary heroic decisions, strategically controlling their subordinates, and providing non-executive directors with pertinent strategic and risk information. Here, risk, as well as strategy, is also managed across the whole organization through this routing system and the creativity of senior managers.

As discussed above, the main attempts made by some researchers have been to demonstrate the interrelation between risk management and management accounting from informational, functional, and organizational viewpoints: broad non-financial and timely information, the routing function, and BSCD. However, it is unclear 
how information on both risk and opportunity, as oppositional aspects of strategy, should be synthesized with accounting profit and loss in management accounting systems as well as how management accounting fulfills its function in the decision-making and performance evaluation processes. Further, it is not clear how this synthesis and integration strengthens the prospective and proactive features of management accounting.

\subsection{Proposal of the COLC Model}

In the light of the controversial issues above, Nishimura (2015a) constructs a model in which profit opportunity and risk information is proactively integrated into accounting profit and loss as part of the decision-making and performance evaluation processes. In the model, strategic activities related to profit opportunities and risks are controlled toward a profit target through multiple planned (long-term and short-term) values, preparatory variance analyses, and indicators of profit improvements (organizational and structural improvements, including cost improvement). This model is called the Comprehensive Opportunity and Lost Opportunity Control (COLC) model. In the model, a proactive and preventive planning process links to profit planning and cost design (in Japanese, genka kikaku) on the basis of the concepts of profit opportunity and risk, while each aspect of performance is controlled with feedforward and feedback loops for lost opportunity or opportunity cost. The COLC model is simply revealed in the following equations (Nishimura, 2015b).

Forecast (long-term or ideal) profit opportunity - estimated (short-term or practical) profit opportunity = forecast profit opportunity variance

Forecast risk (expected loss) - estimated risk (expected loss) = forecast risk variance

Profit improvements are proactively examined by using quantitative and qualitative variance analyses, and effective measures exploiting profit opportunity and mitigating impending risks are incorporated. For example, measures and factors that may be taken into account include external and internal improvements; the external improvement is related to the reorganization of overseas business points or supply chains and the re-examination of import and export policies, while the internal one to new product design, technological innovation, the reorganization of manufacturing and management, cost design, and cost improvement. The allowable or target profit used for this improvement examination can be schematized via the following equations.

(Estimated profit opportunity + improved profit opportunity) - (estimated risk - risk reduction by improvement) $=$ allowable (or target) profit

Enterprises can decide the allowable or target profit with reference to these profit opportunities and risks. In specific cases, allowable profit as an ideal gives the target profit as a practical goal after comparing it with the presently estimated profit and adding some improvements to the original estimated profit when the former is higher than the latter. This target profit provides managers with indicators of opportunity cost for performance evaluation by comparison with actual profit. Before making this comparison, managers can further obtain basic data based on target profit to help in deciding the allowable cost or target cost in cost design.

For manufacturing activities under today's financial risks, it is practical to apply the COLC model to the most influential market risk, namely foreign exchange risk, to clarify the relations between market risks, derivatives, and manufacturing activities. We can then develop the model into a more proactive form, which would allow organizing proactive and preventive measures against potentially disastrous risks and their negative effects on manufacturing activities.

\section{Effects of Foreign Exchange Rate Risks on Manufacturing Performance in Japanese Manufacturing Companies}

Recently, the risk of foreign exchange fluctuation has had a strong influence on corporate performance in Japan. The exchange rate between the Japanese yen and the US dollar has fluctuated from a high of 76.19 yen per dollar in January 2012 to a low of 134.56 yen per dollar in January 2002, well below the annual mean value of 105.55 yen from January 1999 to January 2015. It is clear that the business performance of Japanese manufacturing companies was strongly influenced by this fluctuation. In the 17 years from 1999 to 2015, there were 10 years when the yearly rate of the yen was higher than average and 7 years when it was lower (Note 1). Judging from the exchange rate of the yen against the dollar, a 10-yen depreciation appears to increase operational profit by 658.2 billion yen for the all listed companies in the transportation machinery industry and 886.7 billion yen in the general machine and electric machinery industry. In contrast, operational profits are estimated to decrease by 36.3 billion yen in the hardware and other manufacturing industry and 72.8 billion yen in the wholesale and retail sale industry, which depend strongly on import trade. In the opposite case, the appreciation of the yen might similarly have a negative impact on the business earnings of strongly export-oriented manufacturing companies. According to an investigation by the NLI Research Institute, the negative effect of the appreciation of 
the yen was generally strong in manufacturing industries in January 2011, among which the general machine and precision machine industries were most strongly influenced, followed by the iron, transportation machinery, and electric machine industries (Mizuho ISD, 2014; Ueno \& Aoyama, 2011).

Because the transportation machinery, electric machinery, and industrial equipment industries are representative of overall Japanese manufacturing activities, we aim to clarify the relations between foreign exchange risks and manufacturing activities by examining financial statements and related information from those industries (Note 2). Further, we examine the foreign exchange earnings and the countermeasures taken against related risks by representative companies in these industries. For this, we chose representatives from the top 100 Japanese companies (by sales volume as of March 2015) and some representative companies in the industrial equipment industry that have a much smaller sales volume but have a high level of overseas sales. The results are presented in Table 1 and Table 2.

Table 1. Foreign exchange earnings of key manufacturing industrial companies in fiscal years 2008 and 2014

\begin{tabular}{llcclc}
\hline $\begin{array}{l}\text { Industry (number of } \\
\text { companies) }\end{array}$ & researched & $\begin{array}{l}\text { Companies that } \\
\text { reported foreign } \\
\text { exchange profit }\end{array}$ & $\begin{array}{l}\text { Companies } \\
\text { that reported } \\
\text { foreign } \\
\text { exchange loss }\end{array}$ & $\begin{array}{l}\text { Companies } \\
\text { higher exchange profit } \\
\text { or lower loss than in } \\
\text { previous year }\end{array}$ & $\begin{array}{l}\text { Companies with lower } \\
\text { exchange } \\
\text { greater loss } \\
\text { previous year }\end{array}$ \\
\hline 1 Transportation & 2008 & 5 & 7 & 7 & 5 \\
Machinery (12) & $\mathbf{2 0 1 4}$ & $\mathbf{1 0}$ & $\mathbf{2}$ & $\mathbf{1 0}$ & $\mathbf{2}$ \\
2 Electrical machinery \& & 2008 & 1 & 10 & 6 & 5 \\
apparatus (11) & $\mathbf{2 0 1 4}$ & $\mathbf{8}$ & $\mathbf{2}$ & $\mathbf{6}$ & $\mathbf{4}$ \\
3 Industrial equipment & 2008 & 4 & 7 & 6 & 5 \\
(11) & $\mathbf{2 0 1 4}$ & $\mathbf{5}$ & $\mathbf{5}$ & $\mathbf{7}$ & $\mathbf{4}$ \\
4 Total (34) & 2008 & 10 & 24 & 19 & 15 \\
& $\mathbf{2 0 1 4}$ & $\mathbf{2 3}$ & $\mathbf{9}$ & $\mathbf{2 3}$ & $\mathbf{1 0}$ \\
\hline
\end{tabular}

Note. One company is excluded in the electrical machinery \& apparatus category in fiscal year 2014 because it did not include information on foreign exchange profit or loss in its financial statements. One company is also excluded in the industrial equipment in fiscal year 2014 because it reports zero foreign exchange earnings in its financial statements for fiscal year 2014.

Comparing foreign exchange earnings of the chosen companies in fiscal year 2014 with those earnings in 2008, we can see that in 2008 (strong yen), 70.6\% of these companies were subject to the negative influence of foreign exchange fluctuation and $44.1 \%$ (15) had worse foreign exchange earnings than in the previous year. In contrast, in fiscal year 2014 (weak yen) about 72\% companies were positively affected and had earnings better than in the previous year. In particular, many companies $(83 \%)$ in the transportation machinery industry were favorably affected by the yen's depreciation in fiscal year 2014, showing improved exchange earnings. However, on the whole, many companies were more unfavorably affected by the yen's appreciation in fiscal year 2008, with some companies unable to escape the adverse circumstances resulting from overlapping problems of exchange rate fluctuation and strong price competition from other Asian countries.

At present, generally export-oriented manufacturing companies have increased their revenues following depreciation of the yen and are now strengthening their countermeasures against foreign exchange risks in order to cope with future situations, taking a lesson from the trying experiences of the financial crisis of 2008. As shown in Table 2, most companies conduct hedge accounting and hold non-hedged derivatives. This trend mirrors that of other Japanese industrial companies whose ratio of export dependency is high and is strongly influenced by the risk of foreign exchange fluctuation (Ito, Koibuchi, Sato, \& Shimizu, 2013).

Most of these companies would accept following idea from Panasonic: "risk management activities are closely connected with the planning and implementation of business strategy to surely accomplish business purpose that leads to the advancement of enterprise value" (Panasonic Corporation, 2014, 2015). Similarly, Hino Motors points out in its financial statements that the company may potentially have reduced profit, compared with what could have naturally be achieved, as a result of derivatives trading that was partially undertaken to mitigate the risk of foreign exchange fluctuation but which may instead have exerted a negative influence on business results and the firm's financial condition when purchasing raw materials and selling finished products at home and abroad (Hino Motors, 2015). 
Table 2. Derivatives in major manufacturing companies in Japan in fiscal years 2008 and 2014

\begin{tabular}{|c|c|c|c|c|c|c|c|c|c|c|c|c|c|c|}
\hline \multirow{3}{*}{ Industries } & \multirow{3}{*}{$\begin{array}{l}\text { Risk } \\
\text { Methods }\end{array}$} & \multicolumn{6}{|c|}{ Hedged derivatives } & \multicolumn{7}{|c|}{ Non-hedged derivatives } \\
\hline & & \multicolumn{2}{|c|}{ Currency } & \multicolumn{2}{|c|}{ Interest rate } & \multirow[b]{2}{*}{ SO } & \multirow{2}{*}{$\begin{array}{l}\text { Price } \\
\mathrm{CF}\end{array}$} & \multicolumn{2}{|c|}{ Currency } & & \multicolumn{3}{|c|}{ Interest rate } & \multirow{2}{*}{$\begin{array}{l}\text { Price } \\
\mathrm{CF}\end{array}$} \\
\hline & & $\mathrm{EC}$ & $\mathrm{CS}$ & IS & ICS & & & $\mathrm{EC}$ & $\mathrm{CS}$ & $\mathrm{CO}$ & IS & $\mathrm{IO}$ & Others & \\
\hline \multicolumn{2}{|c|}{$\begin{array}{l}1 \text { Transportation } \\
\text { machinery (12) }\end{array}$} & 8 & 2 & 8 & 1 & & 1 & 12 & 3 & 3 & 5 & 2 & & \\
\hline \multicolumn{2}{|c|}{$\begin{array}{l}2 \text { Electrical machinery } \\
\text { and apparatus }((11)\end{array}$} & 8 & 2 & 7 & & 1 & & 8 & 3 & & 4 & 1 & $\begin{array}{l}\text { ICS } 1 \\
\text { SF } 1\end{array}$ & 1 \\
\hline \multicolumn{2}{|c|}{$\begin{array}{l}3 \text { Industrial equipment } \\
\text { (11) }\end{array}$} & 10 & 2 & 10 & 1 & & 2 & 9 & 3 & & 3 & & $\begin{array}{l}\text { SF } 1 \\
\text { CCS1 }\end{array}$ & 1 \\
\hline \multicolumn{2}{|l|}{ Total (34) } & 26 & 6 & 25 & 2 & 1 & 3 & 29 & 9 & 3 & 12 & 3 & 4 & 2 \\
\hline
\end{tabular}

Abbreviations: $\mathrm{EC}=$ Exchange contract; $\mathrm{CS}=$ Currency swap; IS=Interest rate swap; ICS=Interest rate and currency swap; SO=Stock option; $\mathrm{CF}=$ Commodity futures; $\mathrm{CO}=$ Currency option; $\mathrm{IO}=$ Interest rate option; $\mathrm{SF}=$ Stock futures; $\mathrm{CCS}=$ Cap crossing currency swap.

Yamaha Motor (2015) also describes the potential for hedge trading to cause the loss of profit opportunity due to fluctuation in the foreign exchange rate opposite to what the company assumes. Even though it adopted countermeasures against the risk of foreign exchange fluctuation, Hitachi (2015) rightly notes the potential for ineffective hedge accounting and countermeasures adopted to mitigate the risks of foreign exchange fluctuation, specifically because these measures only put off the negative effects of the risks or give only temporary relief from them. As described above, despite the adoption of hedge accounting, most of the companies cited in the tables above have tried to create a stronger business foundation that is not influenced by external environmental risks. Steps in this direction include the reorganization of bases and supply chains for production and overseas trade, the re-examination of import and export policies, the promotion of new product designs and technological innovation, the reorganization of internal business structures, and the reinforcement of cost design and cost improvement.

For example, to protect against the risk of future foreign exchange fluctuation, Toyota Motor Corporation (2015) has taken steps to strengthen its business foundation through such internal improvements as cost design, cost improvement, and fixed expense reduction under the presently favorable condition of the yen depreciation (see also Toyota Industries, 2015). Imai $(2010 ; 2014)$ designates this fundamental idea as "Toyota-style performance management accounting" and uses the concept of "proactive slack" to shed light on its structure and specific characteristics.

As described at the beginning, in this paper we intend to apply the COLC model to foreign exchange risk management and clarify the new cognitive and control functions of management accounting in risk management. This goal drives us to the question of what accounting form the concepts of hedge accounting, derivatives, and internalized improvements should take in the COLC model and of how foreign exchange risks can be planned for and controlled together with internal profit improvements.

\section{COLC Model and Hedge Accounting}

\subsection{Derivatives and Risk Management}

Derivatives are considered as a useful tool to transform or avoid risk, although their speculative nature and risk are becoming clear as the globalization of their trading, the diversity of financial instruments, and the deregulation of finance/insurance sectors advance. For example, Phillips (1995) considers the complexity of derivative activities as a driver of revolution in risk management practices and states that derivative markets give opportunities to transform market risks (p. 240; see also Gibson, 2007).

However, as the key roles of derivatives in the financial crisis of 2008 and their serious negative influences on global economy became clear, there were many warnings against the dangerous nature of derivatives. For example, Buffett (2002) warns us that "derivatives are financial weapons of mass destruction, carrying dangers that, while now latent, are potentially lethal" (p. 15). He also compares the derivatives business to a "time bomb" and a "hell" that is "easy to enter and almost impossible to exit" (p. 13). According to Sipko (2011), this financial crisis was more serious in its scope and depth than the Great Depression in the 1930s. Moreover, the growth of the global derivatives market was much faster than that of global real GDP (p. 40). Therefore, their transparency and hedge effectiveness have become a strong point of focus (Kawaller, 2002; Johnson, Bullen, \& Kern, 1994) in order to control derivative speculation and strengthen the counterbalance function of derivatives against risk. The synchronic social-control and stronger transparency of derivative activities, along with 
comprehensive risk management, are required for the protection of the real economy and manufacturing foundation. This results in the establishment not only of "new requirements that better reflect the risks and returns from derivatives and other trading activities" (p. 245; see also Cowell, 2006), but also the systematic requirement of comprehensive and effective balancing between derivatives and risks.

These requirements are pushing forward more comprehensive development of risk management and the systemization of an effective economic relation between derivatives and risks, including disclosure, corporate governance, and internal controls. We find these in their most representative form in international accounting standards.

\subsection{Hedging and the COLC Model}

The main purpose of hedge accounting is to insure against market risks by means of derivatives or speculative profit or, alternatively, to use a speculative measure to protect manufacturing activities from external risks (see Frestad \& Beisland, 2015). However, as shown in Table 2, typically companies clearly describe in their financial statements that their derivatives trading is by no means speculative because they conform to accounting standards that allow them to use derivatives as part of risk management strategy. Thus, derivatives are not presently considered as speculative in business circles when they are connected with risk management, even though they cannot intrinsically be separated from speculation. Under IFRS 9, which will take effect in 2018, derivatives are entered into from the viewpoint of enterprise risk management in which enterprise peculiar and positive practices beyond a formal obedience to rules, the restriction of speculation, and sustainable enterprise value creation are included. At the same time, IFRS 9 shifts the fundamental nature of the standard from rules to principles and imposes an effective check on period-income expression distorted by derivatives through the close alignment of derivatives with enterprise risk management and the distinction between fair value hedges and cash flow hedges. Each enterprise, in return for being allowed to use subjective judgement in carrying out hedge accounting and risk management, should prepare definite documents related to hedge measures, hedge objectives, the nature of the hedged risks, how the hedge effectiveness is judged, and the hedge ratio when starting hedge accounting. Additionally, they should retrospectively disclose the objectives, methods, and effectiveness of risk management in financial statements. Consequently, the judgment of hedge effectiveness shifts from a bright-line test of hedge ratio $(0.8-1.25)$ to demonstration of a clear economic relation between hedging measures and hedged items. Risk management must be more intensively implemented from a prospective standpoint rather than a retrospective one (IASB, 2014; McCarrol \& Khatri, 2014; Lombardi, 2010).

As mentioned above, hedge accounting in the near future will be based not only on the reinforcement of prospective and proactive risk management, but also on its close alignment with strategic business planning. Specifically, enterprises should proactively examine profit opportunities and risks that are brought about by enterprise strategy and plan for and control the profit opportunities of derivatives that correspond to enterprise risks (Mercy, 2006). We can represent this relation as follows.

Hedge effectiveness ratio $=$ the fluctuation-range of hedging measure value / the fluctuation-range of hedged item value $\simeq 1$

That is, the effective economic relation in hedge accounting implies that the effectiveness ratio approaches 1 toward infinity, and so it more clearly captures a satisfactory economic relation. According to the COLC model, the hedge effectiveness ratio is shown as follows.

\section{Hedge effectiveness ratio $=$ profit opportunities of derivatives $/$ risks of hedged assets and liabilities}

\section{$\simeq 1$}

Therefore, hedge accounting can also be incorporated into the relation between profit opportunity and risk in the COLC model and thereby become part of the decision-making and performance evaluation process for strategic and risk management. In practice, it may be rare for the return (or profit opportunity) of a hedging measure to be completely balanced against the risk of the hedged item because the objective movement of market risks cannot be guaranteed to coincide with managers' forecast, and speculative inclination cannot be entirely eliminated from entrepreneurs in the present financial environment (see Fujita, 2003; Frestad \& Beisland, 2015; Russell-Jones, 2014). Accordingly, to protect manufacturing activities from derivative speculation and risks, the profit opportunity and risk of derivatives and their effective relation must be managed and disclosed prospectively and retrospectively (Cowell, 2006; Smistad \& Pustylnick, 2012; Kawaller, 2004; Kawaller \& Koch, 2015; see also Metzger, 2009).

\subsection{More Proactive Countermeasures against the Risk of Foreign Exchange Fluctuations}

Many companies cannot conceive of coping with market risks by using only hedge accounting, but instead view 
it as only a temporarily method of delaying market risks. Accordingly, they emphasize building up a stable business foundation that is protected against the risk of fluctuation in foreign exchange rates and interest rates. Toyota carries out an advanced form of this method that focuses on proactively strengthening business adaptability to changing risks in the external business environment by using preventive cost design and cost improvement. Imai (2014) systemizes this idea and method as the concept of "proactive slack" (p. 45). Proactive slack protects against future external business environmental risks, provides sustainable business growth, and contributes to the preservation of the preconditions (revenue drivers) related to the external business environment in profit planning and control processes. Further, it strengthens adaptability to changing external business environmental risks by devising cost reduction schemes connected to the preconditions (Imai, 2014).

Next, we investigate proactive slack, which in Imai's scheme is designated as the "Toyota-style performance management accounting" (2014, p. 44; see also Imai, 2010), by using presumed figures with some amendments to the numerical values and framework to understand it from the angle of the COLC model. In addition, this approach will clarify the model's role in planning for and controlling profit opportunities, risks, and profit improvement activities. Table 3 shows a diagram in which Imai's proactive slack table is reorganized according to the COLC model.

In Table 3, a company forecasts profit opportunities of 15,000 million yen (all currencies here are assumed to be yen) from the viewpoint of long-term and sustainable business growth. The profit opportunity consists of 10,000 million in base profits based on past reliable business results, 4,000 million in internal profit improvements (2,000 million from the sales side and 2,000 million from the manufacturing side), as well as anticipated foreign exchange profits of 1,000 million from the favorable influence of a slumping yen. However, to draw up a more practical plan of profit opportunities and risks, the company should estimate short-term and practical profit opportunities and risks to cope with impending enterprise risks through the examination of actual and future economic data on the business environment and organizational ability. As a result of this examination, the company finds that there is the possibility of sudden appreciation in the yen, which would adversely affect the forecasted improvements in sales volume and selling price. (Although the negative change in these improvements may arise from such internal causes as incorrect planning and control on the revenue side, study of that issue lies outside the scope of this paper.) The effect of this shift is a decrease of 1,500 million in profit, consisting of the disappearance of the 1,000 million in anticipated foreign exchange profits and a reduction of 500 million from improvements on the sales side. However, the company should actualize the incipient forecast profit opportunities to maintain sustainable business growth.

Table 3. Foreign exchange risk and internalized improvement in the COLC model (1) (Millions of yen)

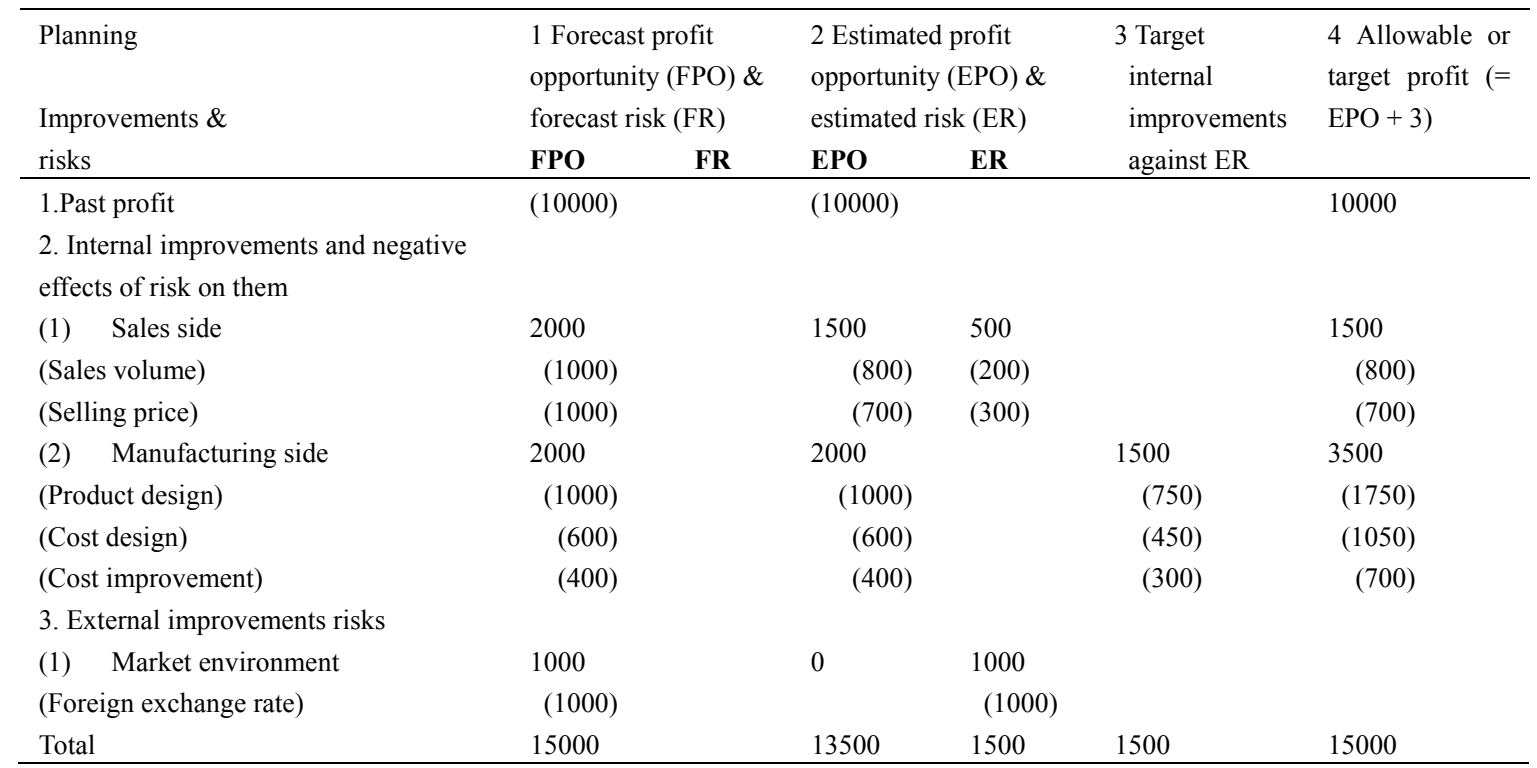

Note. Positive fluctuation of foreign exchange rate (yen depreciation) shows foreign exchange profit in the profit opportunity column, while the negative fluctuation (yen appreciation) shows foreign exchange loss in the risk column.

In Table 3, Imai's concept of proactive slack, in which internal profit improvements outweigh external 
environmental risks, is also incorporated into the general framework of profit opportunity and risk planning, The company should undertake new endeavors to realize improvements in areas such as product design, cost design, and cost improvements to protect the manufacturing foundation from risks, which in this scenario will yield profits of 1,500 million. For example, the company develops new products of high quality (function) and low cost through new cost design and cost engineering and further works to curtail manufacturing costs and fixed expenses through re-examining the production structure, business organization, and supply chain system. After this, the company sets a strategically allowable profit or target profit of 15,000 million so that it can lessen foreign exchange risks and their negative influence on manufacturing performance while strengthening its strong manufacturing foundation against future business environmental risks. Viewed in this light, we can recognize that the allowable or target profit has completely different implications from the incipient forecast amount of profit opportunities, even though they are the same amount (15,000 million) because it is a target that can adequately cope with external business risks and has the ability to control the whole operational and production process so as to change risks into profit improvements or profit opportunities.

In our model, profit opportunity can be defined as the probability that internal profit improvements and external favorable changes in the business environments will yield corporate profit, while risk is the probability that external unfavorable changes of business environment and their negative effects on internal enterprise improvements will result in accounting loss, although risk is generally understood more widely.

Given this context, the terms in the COLC model are concisely explained as follows, using the example from Table 3 (in millions of yen):

Forecast profit opportunity (FPO) - estimated profit opportunity (EPO) = forecast profit opportunity variance

$15,000-13,500=+1,500$

Forecast risk (expected loss) (FR) - estimated risk (expected loss) $(E R)=$ forecast risk variance

$0-(1,000+500)=-1,500$

These two variances show the forecast error of profit opportunities and risks against some changes in the business environment involving profit opportunities and risks. The variance of forecast profit opportunity is related to favorable or unfavorable changes in the business environment and forecast error concerning them, while the variance of forecast risk deals with the new occurrence of risk, the transformation of forecast profit opportunity to risk, their negative effects on forecast profit opportunities and profit improvements, and errors in these forecasts. For the year shown, the estimated profit opportunity results in 1,500 million less than the incipient forecast amount as a result of forecast error concerning foreign exchange fluctuation and its influence on profit improvements. It is clear from these formulations that forecast profit opportunities are influenced by foreign exchange risk and its effects on internal manufacturing performance.

Therefore, the company should pursue more comprehensive improvements (product design, cost design, and cost improvement) totaling 1,500 million more than the estimated profit opportunities in order to establish a strong business foundation for the future against external environmental risks and their negative effects while preserving sustainable business growth. For example, if actual profit were 13,500 million and the allowable profit equaled the target profit, the company cannot eliminate foreign exchange risk and the associated negative effects. Therefore, it must concretely examine lost profit opportunity by using variance analysis and address external risks and profit improvements more strongly in the next year.

Target profit - actual profit $=$ opportunity costs variance

$15,000-13,500=1,500$

If actual profit were 16,000 million as a result of favorable fluctuation in the foreign exchange rate compared with the original forecast, in contrast with the estimation stage, the company could not only establish the same enduring manufacturing foundation assumed in the incipient forecast stage, but could also further invest 2,000 million (1,000 million from the favorable influence on foreign exchange and 1,000 million from additional internal improvement) to establish a stronger manufacturing foundation. The COLC model recognizes the interrelation between the fluctuation risk of foreign exchange rate and profit improvements from the angle of profit opportunity and opportunity cost and provides managers with effective information for risk management and internal improvements. Moreover, its target profit further plays a significant role in estimating target cost for cost design.

\section{Synthetic Development of the COLC Model in Foreign Exchange Risks and Derivatives}

Next, we consider the case where the company suffers a 1,000 million foreign exchange loss from yen 
appreciation as well as losses of 400 million from the negative influence on planned improvements of the sales side (200 million from sales volume and 200 million from selling price). The firm then conducts hedge accounting (a 1,400 derivatives transaction against these risks). We can also present this alternate situation using the COLC model, the result which are shown in Table 4.

Table 4. Foreign exchange risk and internalized improvement in the COLC model (2) (Millions of yen)

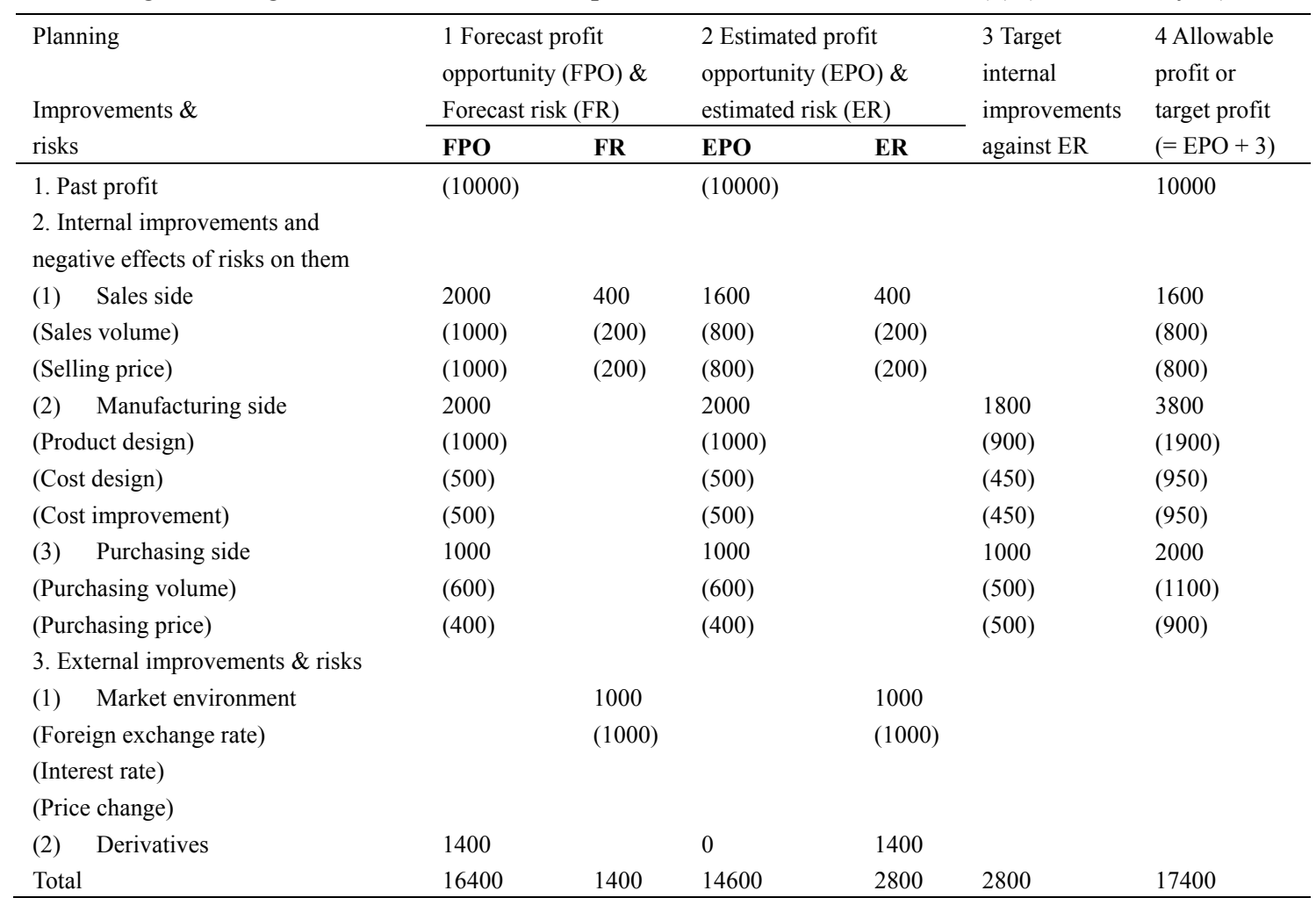

Before turning to Table 4, we must note that the table includes different content from Table 3. "Improvement activities on the purchasing side" has been added to the internal profit enterprise improvements in the first column. This addition is made because most of the manufacturing companies identified in Table 1 establish stable and firm supply chains at home and abroad, where they have strong strategic cooperation with suppliers. As a purchaser, the company synchronizes the development and design of new products with suppliers as producers of parts and components through joint cooperation in value engineering. Therefore, these manufacturing companies can internalize suppliers' improvements into their improvement program through the joint development of product design, cost design and cost improvement (Tanaka; 2015; Nishimura, 2014).

In Table 4, we can see from the second column that the 1,400-million profit opportunity from derivatives is forecasted as hedge accounting against a 1,000-million loss from forecasted foreign exchange risks plus a 400-million loss from the resulting negative effects on sales side improvements (200 million from sales volume improvement and 200 million from selling price improvement). The original amount of improvements on the sales side (2,000 million) is still effective because even though 400 million of the 2,000 forecast amount may be unfavorably influenced by foreign exchange rate risks, these risks are counterbalanced by the profit opportunities of derivatives hedging. In the next column, the practical short-term estimation of profit opportunities and risks shows the probability that the 1,400-million profit opportunities from derivatives hedging will change to an unfavorable situation or risk, while at the same time, the risks of previously hedged items related to foreign exchange risk and their negative influence on the sales side are untied from the derivatives. As a result, foreign exchange risk of 1,000 million and a negative effect of 400 million on the sales side are newly estimated in the third column. Therefore, the company should cope with these risks and their negative effects by further strengthening of internal profit improvements on the manufacturing and purchasing sides to establish the long-term stability of its manufacturing foundation. Therefore, the new improvement target in product design, cost design and cost improvements becomes 2,800 million, consisting of the original risks (1,000 million), the 
original negative influences of these risks on the forecast profit improvements (400 million), and the new risks of derivatives trading failure (1,400 million). As a result, this relation between the forecast and estimated amounts leads to an allowable or target profit of 17,400 million. If this allowable profit materializes, the company will be able to establish a solid real-manufacturing foundation against external business environmental risks by using internal profit improvements, even though serious damage is caused by losses from derivatives trading.

The COLC model plays an important part in planning for and controlling business activities in these processes by taking into account information on profit opportunities, risks, and lost opportunity (opportunity cost). Moreover, allowable profit is compared with estimated profit calculated using practical accounting information and data from middle- and lower-level managers. After considering their variances and proactively undertaking revised countermeasures against risks, this process leads to the target profit and lays the foundation for allowable cost in cost design. Consequently, this internalization of external environmental risks into profit opportunities is carried out through the COLC model and internal profit improvements based on product design, cost design, and cost improvement. The following equations summarize the process above and highlight the figures (in millions of yen) from our example company in Table 4.

Forecast profit opportunities (FPO) - estimated profit opportunities $(E P O)=$ forecast profit opportunity variance

$16,400-14,600=+1,800$ (forecast error from derivatives trading and the lost profit opportunities in profit improvements that are influenced by foreign exchange risks as a result of the failed derivatives)

In the forecast profit opportunities and risks, the prospective effectiveness of hedge accounting is included as follows:

(Profit opportunities of derivatives - foreign exchange rate risk) $=1,400-1,400=0$

Forecast risk $(F R)$ - estimated risk $(E R)=$ forecast risk variance

$1,400-2,800=-1,400$.

These are the risks that result from failed derivatives trading and the reappearance of original negative effects on sales side improvements, or the new appearance of the negative effects of foreign exchange risks on sales side improvements that were counterbalanced or hidden at the incipient forecast stage by derivatives.

The forecast risk variance of 1,400 million represents the decrease in profit opportunities by the ineffectiveness of derivatives, including the reappearance of the negative effect of foreign exchange risk on profit improvements (assets or liabilities) of 400 million, against which the company originally hedged with derivatives. This variance information, together with forecast profit opportunity variance, warns managers against risks that exceed this decrease in the forecast profit opportunity. Therefore, the company should plan to increase internal profit improvements by 2,800 million beyond the incipient estimated profit opportunity to establish a stronger manufacturing foundation that can withstand external environmental risks and their negative effects. The estimated risk of 2,800 million informs managers of the necessary internal level of improvements needed to maintain a durable manufacturing foundation. If the company achieves this target profit of 17,400 million based on this 2,800 million in risks, it can establish a stable and durable manufacturing foundation by internal profit improvements, irrespective of the ineffectiveness of derivatives. However, the company should always preserve "slack" with which external business environmental risks can be internalized into profit improvements. In this sense, it should also always establish the manufacturing and management structures needed to implement external and internal improvements. Additionally, the planning process for profit opportunity and risk leads to target profit and target cost as follows.

Estimated profit opportunities + internal profit improvements $=$ allowable profit

$14,600+2,800=17,400$ (allowable profit)

The forecast and estimated profit opportunities and risks, along with the improvement target through variance analysis, give the calculation foundation for target profit. To make sure, we indicate the relation between the COLC model and cost design (target costing) as follows.

Allowable profit - estimated profit $=$ forecast profit variance $\longrightarrow$ proactive profit improvements

Estimated profit + proactive improvement amounts $=$ target profit

Target profit - actual profit $=$ profit variance (opportunity cost variance)

Target profit $\longrightarrow$ allowable cost

Allowable cost - estimated cost $=$ forecast cost variance $\longrightarrow$ proactive cost improvements 


\section{Estimated cost - proactive improvement amount $=$ target cost}

\section{Target cost - actual cost $=$ cost variance (lost profit opportunity)}

Incorporating the COLC model into management accounting gives profit and cost targets for improvements in businesses and future improvements on the basis of information about profit opportunities and risks, controls business activities according to these targets, and evaluates their performances in terms of opportunity and lost opportunity (opportunity cost). These planned values are always collated with actual data and information from middle- and lower-level management and from workers.

As mentioned above, practical improvements are estimated after multiple planned (long-term/ideal and short-term/practical) values of profit opportunities and risks are examined and compared from the viewpoint of opportunity and lost opportunity. This then gives decision-makers more practical information on estimated profit opportunities and risks by connecting these profit improvements to the original estimated values. This process allows companies to identify a target profit and target cost and to make better use of cost design and cost improvements, backed with profit opportunities and lost opportunities (opportunity costs). In a strong finance-oriented economy, this model incorporates market risks into systems of management accounting and urges managers to develop strong improvement activities to protect their manufacturing foundation from external risks. The approach put forth in this paper may give impetus to not only the protection of firms' manufacturing foundations from market risks, but also improvements and innovation in manufacturing technology and organization. At the same time, a company can compile a strategy and risk report in a simpler form for stakeholders on the basis of the COLC model and its table (see also Nishimura, 2015a).

\section{Conclusion}

The COLC model uses the comparison and analysis of profit opportunity and risk to identify improvement measures, proactively arrange for and implement such measures, and connect the optimum value of profit opportunity with the traditional methods of profit and cost management. The inclusion of the COLC model in management accounting can broaden managers' global and long-term outlook on decision-making and performance evaluation. This also contributes to the protection and strengthening of manufacturing activities under the strong uncertainty and financial risks of the contemporary global economy.

Concerning market risk management in management accounting, much remains to be argued and discussed because enterprises cannot perfectly manage external risks by using hedge accounting and the COLC model. Not only do risks in the external business environment ceaselessly increase both in quantity and in scope, but these changes also rise above the ability of humans to forecast completely. Derivatives, by their complicated and nontransparent nature, can act as a ticking "time bomb" in the economy, with the resulting damage worse than in the Great Depression of the 1930s. Because at present management accounting cannot manage market risks alone by looking at internal business effectiveness and efficiency, management accountants should broaden their horizons towards global and long-term changes in social and economic structures. At the same time, just as hedge accounting and derivatives should be carried out as part of a comprehensive strategy of risk management, corporate governance and internal controls, and in close conformity with international and domestic accounting standards, so should management accounting adhere more closely to financial accounting and be more socially and economically oriented. Management accounting should strive to be sufficiently conscious of not only efficiency, effectiveness and profitability, but also disclosure, transparency, and social responsibility. It should shift from a retrospective, explanatory, and procedural standpoint to prospective, proactive, socially aware, and creative one (Nishimura, 2015a). Management accounting science, like other social science, goes on a journey from contradiction to harmony. In a system where the COLC model joins hands with such global and long-term perspectives and methods, it may contribute towards such new direction in management accounting, even though it is only a step for harmony and balance among the many contradictable and uncertain conditions present.

\section{Acknowledgements}

This paper owes much to the theoretical framework that Professor Imai represented diagrammatically about "proactive slack" in the conference of the Japanese Association of Management Accounting at Fukuoka (May 2015).

\section{References}

Bhimani, A. (2009). Risk management, corporate governance and management accounting: Emergence interdependences. Management Accounting Research, 20(1), 2-5. http//dx.doi.org/10.1016/j.mar.2008/11.002

Buffet, W. (2002). Warren Buffett's Letters to Berkshire Shareholders. Berkshire Hathaway, Inc. Retrieved from 
http://www.berkshirehathaway.com/letters/2002.html

Cowell, F. (2006). Risk management for derivatives. Derivatives Use, Trading \& Regulation, 12(3), 228-243.

Frestad, D., \& Beisland, L. A. (2015). Hedge Effectiveness Testing as a Screening Mechanism for Hedge Accounting: Does it Work? Journal of Accounting, Auditing \& Finance, 30 (1), 35-56.

Fujita, K. (2003). Effectiveness and Limitation of Hedging Accounting. Ritsumeikan Keieigaku, 42(2), 1-18.

Gibson, M. S. (2007). Credit Derivatives and Risk Management. Economic Review, 25-40.

Hino Motors Ltd. (2015). Annual Securities Report. Retrieved from http://www.kabupro.jp/mark/2015622/S10050CE.htm

Hitach Ltd. (2015). Annual Securities Report. Retrieved from http://www.kabupro.jp/edp/20150625/S10055M4..htm

IASB (International Accounting Standard Board). (2014). IFRS 9 Financial Instruments. Retrieved from http://www.iasplus.com/en-gb/standards/ifrs-en-gb/ifrs9

Imai, N. (2010). Proposal of Dual Mode Management Accounting Model: With a view to dissolve "accounting lag. Meijo Journal, 10(4), 61-87.

Imai, N. (2014). Concept of Proactive Slack: A Study on Essence on Toyota's Performance Accounting. Journal of Japan Management Diagnosis Association, 14, 41-46.

Ito, T., Koibuch, S., Sato, K., \& Shimizu, J. (2013). Exchange Rate Exposure and Exchange Rate Risk Management: The Case of Japanese Exporting Firms. The Research Institute of Economy, Trade, and Industry, Discussion Paper Series, 13-E-025. Retrieved from http://www.rieti.go.jp/en/

Johnson, L. T., Bullen, H. G., \& Kern, V. W. (1994). Hedge Accounting: Is Deferral the Only Option? Journal Accountancy, 177(1), 53-58.

Kawaller, I. G. (2002). Hedge Effectiveness Testing: Using Regression Analysis. AFP Exchange, 22(5), 62-68.

Kawaller, I. G. (2004). Ways to Test Hedge Effectiveness: Reconsidering Regression Analysis. AFP Exchange, 24(3), 62-63.

Kawaller, I. G., \& Koch, P. D. (2013). Hedge Effectiveness Testing Revisited. Journal of Derivatives, 21(1), 83-94.

Kim, S., \& Collier, R. (2013). Risk and risk management in management accounting and control. Management Accounting Research, 24(2), 82-87. http://dx.doi.org/10.1016/j.mar.2013.04.003

Lombardi, L. J. (2010). Monitoring Changes in Capital and Hedge Effectiveness under Fair Value Accounting Principles. North American Actuarial Journal, 14(1), 1-15.

Mc Carrol, J., \& Khatri, G. R. (2014). Aligning Hedge Accounting with Risk Management. Accounting Ireland, 46(2), 36-38.

Mercy, S. (2006). Failures Continue Evaluating Hedge Effectiveness, SEC Official Says. Accounting Policy \& Practice Report, 2(25), 1-2.

Metzger, L. (2009). Measuring Hedging Effectiveness for Derivatives. Journal of Government Financial Management, 58(4), 48-53.

Mizuho ISD. (2014). How Do We Consider Strong Yen’ Influences? Mizuho Short Industry Focus, 120, 1-5. Industrial Survey Division (ISD) of Mizuho Corporate Bank, Retrieved from http://www.mizuhobank.co.jp/corporate/bizinfo/industry/pdf/msif_120.pdf

Nishimura, A. (2011). Uncertainty and Management Accounting: Opportunity, Profit Opportunity and Profit. Asia-Pacific Management Accounting Journal, 6(1), 81-102.

Nishimura, A. (2014). Transforming cost design into environmentally conscious cost design in Japan: Likelihood and problems for further development. Journal of Management Control, 25(1), 55-75. http//dx.doi.org/10.1007/s00187-014-0190-x

Nishimura, A. (2015a). Comprehensive Opportunity and Lost Opportunity Control Model and Enterprise Risk Management. International Journal of Business and Management, 10(8), 73-87. http://dx.doi.org/10.5539/ijbm.v10n8p73

Nishimura, A. (2015b). Strategic Management Accounting and Feed-forward Management: With Reference to 
the Unified Management of Profit Opportunity and Risk. Global Management, 3\&4, 1-19.

Panasonic Corporation. (2014). Sustainability Report (pp. 20-25). Retrieved from http://www.panasonic.com.jp/corporate/sustainability/downloads/back_number/pdf/2014/sr2014j.pdf

Panasonic Corporation. (2015). Annual Securities Report. Retrieved from http://www.kabupro.jp/mark/2015626/S100562ZF.htm

Phillips, S. M. (1995). Derivatives and Risk Management: Challenges and Opportunities. Northwestern Journal of International Law \& Business, 15(2), 239-247.

Rasid, S. Z., Isa, C. R., \& Ismail, W. K. W. (2014). Management accounting systems, enterprise risk management and organizational performance in financial institutions. Asian Review of Accounting, 22(2), 128-144. http://dx.doi.org/10.1108/ARA-03-2013-0022

Russell-Jones, M. (2014). Financial risk management: Derivatives. Governance Directions, 81-84.

Seal, W. (2006). Management accounting and corporate governance: An institutional interpretation of the agency theory. Management Accounting Research, 17(4), 389-408.

Shank, J. R., \& Miguel, J. G. (2009). Financial and managerial Accounting, Strategic Cost management and Enterprise Risk Management under SOX. The Journal of Corporate Accounting \& Finance, 83-99.

Sipko, J. (2011). Derivatives and the real economy. Creative and Knowledge Society/Industrial Specific Journal, 1(1), 33-43. http://dx.doi.org/10.2478/10212-011-0003-7

Smistad, R., \& Pustylnick, J. (2012). Hedging, Hedge Accounting and Speculation: Evidence from Canadian Oil and gas Companies. Global Journal of Business Research, 6(3), 49-62.

Tanaka, M. (Ed.) (2015). Cost Design and the Development Strategy of Purchasing. Chuokeizai Publisher, Japan: Tokyo.

Toyota Industries Corporation. (2015). Annul Securities Report. Retrieved from http://www.kabupro.jp/mark/20150611/S1004VXD.htm

Toyota Motor Corporation (2015). Annual Securities Report. http://www.kabupro.jp/mark/20150624/S1005156.htm

Ueno, T., \& Aoyama, S. (2011). Influences of Strong Yen on Enterprise Management: Findings of Questionnaire Research by Nissay Co. in January. NLI Research Institute Report, 16-21.

Woods, M. (2008). Linking risk management to strategic controls: A case study of Tesco plc, International Journal of Risk Assessment \& Management, 7(8), 1074-1088.

Yamaha Motor Co. Ltd. (2015). Annual Securities Report. Retrieved from http://www.kabupro.jp/mark/2015327/S1004DPT.htm

\section{Notes}

Note 1. The data that are quoted here come from Yahoo! Finance: Japanese yen to American dollar [USDJPY] Foreign Exchange. Each exchange rate is the closing price (mean value) on January 1 of each year from 1999 to 2015. Average rates also depend on these prices. http://info.finance.yahoo.co.jp/history/?code=USDJPY\%3DX\&sy=199

Note 2. Annual securities reports of companies in Table 1 and 2 are obtained from the data of EDINET (Electronic Disclosure for investors' NET work): http://disclosure.edinet.fs.go.jp and KABUPRO: http://www.kabupro.jp

\section{Copyrights}

Copyright for this article is retained by the author(s), with first publication rights granted to the journal.

This is an open-access article distributed under the terms and conditions of the Creative Commons Attribution license (http://creativecommons.org/licenses/by/3.0/). 